\title{
Male physicians treating Female patients: Issues, Controversies and Gynecology
}

Jacques Balayla*

\section{INTRODUCTION}

The most precious and sacred form of personal information that we possess is our body. It is our own flesh and blood, which holds and sustains our being. Our body is our instrument for living. It is so personal and intimate that we frequently hide it, as though its public display would be a natural source of shame. Michel de Montaigne, the French Renaissance author, puts it well: "Man is the sole animal whose nudity offends his own companions and the only one who, in his natural actions, withdraws and hides himself from his own kind" (1).

Thus, it not surprising that visiting a physician and allowing for an intricate inspection and examination of our dearest possession, our body, is a source of trepidation and anxiety for us. Perhaps the deepest level of vulnerability in an exam is the genital and pelvic examination. A glimpse into history demonstrates that until very recently, pelvic examinations in women were handled by females, likely to ensure comfort and privacy all the while preventing improper interactions from male counterparts.

\section{HISTORICAL PROGRESSION OF THE PELVIC EXAMINATION}

The oldest medical text known to man is the "Kahun Gynecological Papyrus", written by the Egyptians around 1800 BCE. The papyrus provides a glance into early gynecological medicine and unveils the traditions of reproduction, conception and delivery in ancient Egypt. For the Egyptians, the main treatment modalities provided by the

*To whom correspondence should be addressed:

Jacques Balayla

McGill University Faculty of Medicine

jacques.balayla@mail.mcgill.ca "swnw" (pronounced sounou, physician figure) were founded on pharmacopoeia from animals, plants and minerals; surgical intervention was never recommended (2). Magic spells were whispered, as it was believed that diseases were demonic in origin.

Due to compliance with religious doctrine, men were not allowed to be present at births or at other rituals that dealt with the intimate parts of a woman. Instead, it was the role of the midwife to take care of women and to assist them with their gynecological needs. Interestingly enough, the "Kahun Papyrus" provides some of the earliest evidence of midwifery in history.

Similarly, in the middle ages, it was often the norm for a woman's sexual organs to be examined by midwives, nurses or other females who previously had had similar problems to the patient's. By the early 1800's, with the advent of modern medical degrees and physical examinations, the pelvic exam began to be performed by male physicians, as women were not allowed to enroll in medical school. However, this examination was a variation of the modern version as it consisted of a "compromise" in which the physician kneeled before the woman but did not directly inspect her genitals, only palpated them. In addition, it was during this period that the use of a chaperone became a part of the clinical examination. The chaperone's role was to emotionally support and reassure the patient during a procedure that she found embarrassing or uncomfortable. The chaperone also acted as a witness in cases of malfeasance by the physician. Today, in many parts of the world where religious and cultural precepts often discourage female encounters with male physicians, chaperones still attend gynecological examinations. 
By the 1970 's, only $9 \%$ of enrolled medical students in the United States were women (3). The numbers have drastically increased since then: now $58 \%$ of medical students are women (4), yet there are still disparities in gender among the specialties. In Obstetrics and Gynecology, female residency enrolment rates have quadrupled from 1978 to the present, leaving men in the minority (women account for $71.8 \%$ of Obs/Gyn residents today). Between 1989 and 2002, the proportion of female Ob/Gyn residents rose from $44 \%$ to $74 \%$ while the proportion of female graduating medical students only increased from $33 \%$ to $44 \%$ (5).

As though influenced by the media, the observed trend among medical school graduates today is one where males are over-represented in surgical specialties and females are overrepresented in Obstetrics \& Gynecology and Pediatrics, practices typically associated with the maternal role. Hence, it is well observed that throughout history and up until recent years, the male role in gynecology has been absent, indirect, or directly overlooked by a third party.

\section{A DISPROPORTIONATE REPRESENTATION: REQUIRED OR STEREOTYPICAL?}

The question of why female physicians are more attracted than men to Obstetrics \& Gynecology programs is an interesting one. Is there truly a belief that women in the population are more comfortable being treated by women, especially in the context of sexuality? Or is this over-representation rooted in the desire of female doctors to project their own image and health onto the women that they treat? Conceivably, as Dr. Nelson Soucasaux puts it, it may be due to the fact "...that a great number of men have considerable psychological problems in relation to women and that the male psyche is naturally directed towards the female sex" (6) which makes some men uncomfortable and less willing to make a living treating women. While the true source of this disproportionate representation remains unclear; the literature provides interesting insight into societal views on the subject: A study from the department of Obstetrics and Gynecology from the University of Connecticut found that $66.6 \%$ of patients had no gender bias when selecting an obstetrician-gynecologist. In addition, $80.8 \%$ of patients felt that gender did not influence quality of care (3). These numbers suggest that there are factors other than gender that come into play when choosing a gynecologist. As demonstrated in the primary care literature, interpersonal style and communication appear to be the most important traits in physicians rather than gender (7).

\section{THE MALE MEDICAL STUDENT PROBLEM}

Clinicians have, consciously or unconsciously, come to realize that less negotiation for consent to involve a student in a pelvic examination will be needed if the student is female (8). A study from the Kingston General Hospital showed that $72.8 \%$ of clinic patients reported they would accept an intimate examination by a medical student of either gender, compared with only $32.1 \%$ of high school students. In addition, $22.2 \%$ of clinic patients indicated they would only accept a female student, in comparison to $55.3 \%$ of high school students who would do the same. This seemingly contradictory result demonstrates that as women move forward through the life cycle, gender bias is less observed. In reality, the proportion of subjects preferring female medical students was inversely related not to age, but rather to the number of previous breast or pelvic examinations (9).

Regardless of gender preference, various statements supporting medical student participation in intimate physical examinations were rated as "important" or "very important" by the majority of clinic patients and secondary school students alike.

Over the last two decades there has been an increase in demand for gynecologists and other women's health specialists. Though enrolment rates continue to rise in North American residency programs, waiting lists for screening tests and other basic gynecologic procedures are still markedly long. One of the many ways to respond to this demand is to foster the male interest in the specialty in medical students, in the hopes to augment the male enrolment rate later on. Why males specifically? Evidence shows that any stigma associated with being a "male gynecologist" is no longer accounted for, as the vast majority of patients don't necessarily prefer a female gynecologist over a male one. This misperception has been reinforced over the years by anti-male obstetrician-gynecologist biases in articles and advertisements published in popular women's magazines. Unfortunately, men in particular appear to be influenced by what they perceive as patient desire and the trends of the profession (9).

Positive early experiences with pelvic exams and general gynecology are a key determining factor in pushing a male medical graduate to consider a career in gynecology. Studies have shown that teaching programs involving 
professional patients are superior to teaching and learning on plastic models for both psychological and practical purposes. Furthermore, evaluation of student skills following the learning of examination techniques with professional patients compared with those who received training on office or clinical patients showed superior performance among the first group (10).

\section{WHY WOMEN SHOULD ACCEPT AND ACTIVELY SEEK OUT MALE GYNECOLOGISTS}

A study from the American Journal of Medicine reports that male obstetriciangynecologists claim longer visits with female patients than do female obstetrician-gynecologists, and exhibit more patient partnership behavior, suggesting that physician behavior and medical education can be adapted to further address patient needs (11). A different study from the Johns Hopkins school of Public Health suggests that in comparison to female obstetrician-gynecologists, male ones "were more likely to check that they understood the patient through paraphrasing and interpretation and to use orientations to direct the patient through the visit [...] Male physicians expressed more concern and partnership than female physicians" (12). In fact, men might even have a heightened sensitivity about the distress that a gynecological exam can cause as they themselves have never undergone one. Something as routine as a Pap smear can be a really difficult experience for some women, and some men might go more out of their way to be gentle and explain what they're doing than female gynecologists, who may feel it's not that big of a deal because they've been through the process themselves.

Finally, between the years 1998 and 2003, male and female graduating Obs/Gyn residents were both increasingly more likely to pursue fellowship training rather than enter the general $\mathrm{Ob} /$ Gyn workforce, and these rates were consistently higher for men than they were for women (5). In other words, when a female patient requires gynecological tertiary care, she is more likely to be treated by a male physician and her attitudes towards this fact may impinge on the quality of care she receives. Hence, as multiple advantages of having a male gynecologist exist, our society should continue to embrace the practice of male gynecologists and further promote their positive role in the maintenance of women's health.

\section{CONCLUSION}

While the historical role of men in gynecologic procedures has been ambiguous, there is sufficient evidence in the literature today that demonstrates a gynecologist's gender is not an issue, as other characteristics of the physician, like communication and personal style take precedence. The therapeutic relationship between a woman and her gynecologist can be replete with subtleties regardless of the gynecologist's gender. While the role of gender in this therapeutic relationship remains controversial, male gynecologists continue to demonstrate an equal, and sometimes increased ability to provide high-quality care for women.

\section{REFERENCES}

1. Foglia, Marc, "Michel de Montaigne", The Stanford Encyclopedia of Philosophy (Winter 2009 Edition), Edward N. Zalta (ed.), URL = <http://plato.stanford.edu/archives/ win2009/entries/montaigne/>.

2. Haimov-Kochman R, Reproduction concepts and practices in Ancient Egypt mirrored by Modern Medicine. European Journal of Obstetrics and Gynecology and Reproductive Biology 2005; 123():3-8.

3. Johnson A, Do Women Prefer Care From Female or Male Obstetrician-Gynecologists?. Journal of the American Osteopathic Association 2005; 105(8):369-379.

4. Dalley B, The Joint Admission Medical Program: A State-wide Approach to Expanding Medical Education and Career Opportunities for Disadvantaged Students. Academic Medicine 2009; 84(10):1373-1382.

5. Gerber $\mathrm{S}$, The evolving gender gap in general obstetrics. American Journal of Obstetrics and Gynecology 2006; 2006():1427-1430.

6. Soucasaux, N. Psychological dynamics of the gynecologist-patient relationship. Museum of Menstruation and Women's Health. N.p., 10-2006. Web. 12 Mar 2010. <http://www.mum.org/sopsygyn.htm>.

7. Howell E, Do Women Prefer Female Obstetricians?. Obstetrics and Gynecology 2002; 99(6):1031-1035.

8. Rowe T, The Male Medical Student Problem. Journal of Obstetrics \& Gynecology Canada 2008; 30(10):873-874.

9. Racz J, Gender Preference for a Female Physician Diminishes as Women Have Increased Experience With Intimate Examinations. Journal of Obstetrics and Gynecology Canada 2008; 30(10):910-917.

10. Wanggren $\mathrm{K}$, Teaching medical students gynecological examination using professional patients-evaluation of students' skills and feelings. Medical Teacher 2005; 27(2):130-135.

11. Fang $M$, Are Patients More Likely to See Physicians of 
the Same Sex? Recent National Trends in Primary Care Medicine. American Journal of Medicine 2004; 117():575581.

12. Roter D, Effects of Obstetrician Gender on Communication and Patient Satisfaction. Obstetrics \& Gynecology 1999; 93():635-641.

Jacques Balayla (M.D., C.M. candidate 2012) is currently a second year medical student at McGill University. He serves as Vice President of Student Affairs for the McGill University Medical Students' Society. He is passionate about Women's health issues as well as patient psychology and hopes to pursue research in these areas upon graduation. 